\title{
Numerical Study on the Deformation of a Twin-Track Tunnel Subjected to Adjacent Excavation of Foundation Pit
}

\author{
Yutao BAI ${ }^{\text {a }}$, Yue TU ${ }^{\text {a }}$, Fei GAO ${ }^{\text {a }}$, Meng ZHOU ${ }^{\text {a }}$ and Yongyang ZHU ${ }^{\text {b, } 1}$ \\ ${ }^{a}$ Nanjing Power Supply Company, State Grid Jiangsu Electric Power Co., Ltd., \\ Nanjing 210005, China \\ ${ }^{\mathrm{b}}$ Key Laboratory of Ministry of Education for Geomechanics and Embankment \\ Engineering, Hohai University, Nanjing, 210098, China
}

\begin{abstract}
As well known, foundation pit excavation influences the stress and deformation of adjacent soil, and thus existing tunnel. However, the behavior on the deformation of a twin-track tunnel subjected to adjacent excavation is not clear. In order to investigate this behavior, a series of numerical simulations using PLAXIS are conducted in this study. The result shows that the displacement and internal forces near the foundation pit is almost double those far away. Moreover, as the depth of excavation reaches the burial depth of tunnel, the value of displacement of tunnel begins to increase markedly.
\end{abstract}

Keywords. Excavation of foundation pit; twin-track tunnel; deformation

\section{Introduction}

In recent years in China, urban construction shows great development and various kinds of deep and large foundation pit projects are increasing. However, the excavation of foundation pit will not only affect the safety of adjacent buildings, but also threaten the safety of urban underground drainage pipes, cables, gas pipes and the normal operation of nearby roads. In the process of the excavation of an foundation pit, the horizontal stress of the soil around the foundation pit is unloaded continuously because of the excavation of the soil in the pit, which leads to the decrease of the volume stress of the soil and the increase of the shear stress, resulting in a large deformation of the surrounding soil. Existing studies have found that the settlement of soil around an foundation pit is directly dependent on the lateral displacement of the supporting structure, and its sphere of influence (horizontal and vertical direction) is generally 2-3 times of the excavation depth $[1,2]$.

The stress change of the surrounding soil caused by the excavation of an foundation pit certainly has a non-negligible effect on the deformation of the tunnels during operation. Especially when a deep foundation pit is excavated, the impacts turn out more significant because the depth of deep foundation pit is close to the buried depth of tunnel. Burford first reported that the surface uplift of London subway tunnel

\footnotetext{
${ }^{1}$ Yongyang Zhu, Nanjing Power Supply Company, State Grid Jiangsu Electric Power Co., Ltd., Nanjing 210005, China; E-mail: zhuyongyang2016@outlook.com.
} 
was $50 \mathrm{~mm}$ in 27 years because of the digging of the foundation pit above it [3]. Chang et al. analyzed the accident of tunnel damage caused by the digging of adjacent foundation pit in Taipei subway, and put forward some control suggestions for the excavation of a deep foundation pit besides a metro [4]. Sharmaet al. studied the characteristics of MRT tunnel affected by large-scale excavation at the upper side in Singapore [5]. Also, many studies have analyzed the effects of the excavation of a deep foundation pit on tunnels nearby by means of field monitoring these years in Chins. At the same time, based on engineering experience and measured results, a number of methods for controlling the impacts have been proposed and go for engineering. In addition, many scholars have done research on the interaction between an operating tunnel and a deep foundation pit by numerical methods [6]. However, the above research mostly concentrates on the effect of the excavation of foundation pits on adjacent single tunnel, while that on adjacent two horizontal twin-track tunnels is not clear yet.

Based on the above analysis, combined with specific projects in Shenzhen area, this paper studied the characteristics of the impacts on adjacent horizontal twin-track tunnel when a foundation pit is excavated by numerical methods, and simulated the bending moment, shear force and deformation law of shallow buried twin-track tunnel in the construction process, so as to provide theoretical guidance for subsequent similar projects.

\section{Numerical Simulation}

\subsection{Model Size}

The proposed site lies east side of Xinzhou Road, Futian District, Shenzhen. The main building is planned to be built with 24 floors and four basements. The depth of excavation is about $18 \mathrm{~m}$. The horizontal distance between the red line boundary of the land on the south side of the site and the boundary of an existing subway tunnel is only $6.2 \mathrm{~m}$. The subway tunnel in this section is a shield tunnel with a depth of about $16 \mathrm{~m}$. The centre distance between the left and the right tunnels is $12.5 \mathrm{~m}$, and the distance from the edge line of the foundation pit is only about $10 \mathrm{~m}$.

In order to minimize the impact on subway tunnels, the designed support system of the foundation pit is occlusal pile combined with internal bracing. Pile diameter is $1200 \mathrm{~mm}$ and reinforced pile center distance is $2000 \mathrm{~mm}$. The internal support adopts reinforced concrete support. Two vertical supports are arranged. The elevation of the first support (relative to the ground) is $-2.4 \mathrm{~m}$, and the size of the support section is $0.6 \mathrm{~m} \times 0.8 \mathrm{~m}$. The second support elevation is $-9.5 \mathrm{~m}$, and the size of the support section is $0.6 \mathrm{~m} \times 0.8 \mathrm{~m}$, and the transverse spacing of the support is about $5 \sim 9 \mathrm{~m}$. A crown beam with the cross section size of $1.0 \mathrm{~m} \times 0.8 \mathrm{~m}$ is set on the top of the foundation pit and the waist beam of the that is $1.0 \mathrm{~m} \times 1.0 \mathrm{~m}$ reinforced concrete waist beam.

Considering the simulation process, this paper adopted some assumptions: 1) the soil permeability coefficient is isotropic; 2) The physical and mechanical properties of the soil layer are isotropic; 3) The thickness of underground aquifer shall be taken to the top surface of moderately weathered granite; 4) The dewatering and excavation of foundation pit are plane strain problems; 5) Not considering the time factor, only the deformation after the stabilization of precipitation curve and excavation is calculated. 
It shows the analysis model of the section in figure 1. The distance from the foundation pit to the model boundary is no less than $2 \mathrm{H}(\mathrm{H}$ is the depth of the foundation pit), and the horizontal distance from the model boundary to the tunnel parallel to the subway tunnel is greater than $\mathrm{h}$ ( $\mathrm{h}$ is the depth of the bottom margin of the tunnel). The distance from the bottom boundary of the model to the bottom edge of the foundation pit is more than $2 \mathrm{H}$ (bottom of moderately weathered granite layer). The width of the cross-section foundation pit is $40.1 \mathrm{~m}$. A uniform load of $20 \mathrm{kPa}$ is set outside the foundation pit.

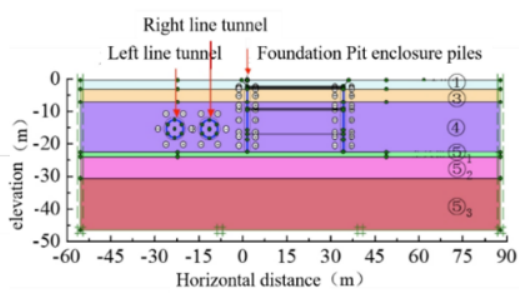

Figure 1. Numerical model of the sequential excavation of foundation and the double-track tunnels.

\subsection{Material Properties}

The material parameters of the support system of the foundation pit and enclosure and metro tunnel lining are shown in table. 1. The outer diameter of the tunnel is set as $6 \mathrm{~m}$ and the thickness is $0.3 \mathrm{~m}$. The enclosure structure is simplified as a continuous wall of equal thickness with a depth of $24 \mathrm{~m}$. Its thickness is equivalent to the bending stiffness of the drilled interlocking pile in its main stress direction (normal direction of the foundation pit retaining surface), and the calculation formula is as follows:

$$
h=0.838 D(\sqrt[3]{1 /(1+t / D)})
$$

Where $\mathrm{D}$ is the diameter of the bored pile. $\mathrm{T}$ is the net distance of reinforced piles. The thickness of continuous wall was calculated to be $848 \mathrm{~mm}$. The cross-section size of the two supports is $0.6 \mathrm{~m} \times 0.8 \mathrm{~m}$, and the transverse spacing is $9.0 \mathrm{~m}$.

Each soil layer is assumed to be an elastoplastic body, and the failure criterion of the material is Mohr-Coulomb criterion. Based on the comprehensive survey report and engineering practice, the soil material parameters are shown in table 2.

Table 1. Physical and mechanical parameters of structural elements.

\begin{tabular}{|c|c|c|c|c|}
\hline Artifacts & Material & $\begin{array}{l}\text { Elastic Modulus } \\
\text { E (GPa) }\end{array}$ & $\begin{array}{l}\text { Poisson 's ratio } \\
v\end{array}$ & Section Parameters \\
\hline Tunnel lining & $\mathrm{C} 50$ & 34.5 & 0.2 & $\begin{array}{l}\mathrm{EA}=1.04 \times 107 \mathrm{kN} / \mathrm{m}, \\
\mathrm{EI}=7.76 \times 104 \mathrm{kN} \cdot \mathrm{m} 2 / \mathrm{m}\end{array}$ \\
\hline Pit supporting & $\mathrm{C} 15 / \mathrm{C} 30$ & $22 / 30$ & 0.2 & $\begin{array}{l}\mathrm{EA}=1.87 \times 107 \mathrm{kN} / \mathrm{m}, \\
\mathrm{EI}=1.12 \times 106 \mathrm{kN} \cdot \mathrm{m} 2 / \mathrm{m}\end{array}$ \\
\hline First support & $\mathrm{C} 25$ & 28 & 0.2 & $\begin{array}{l}\mathrm{EA}=1.34 \times 107 \mathrm{kN} \\
\text { spacing }=9 \mathrm{~m}\end{array}$ \\
\hline
\end{tabular}




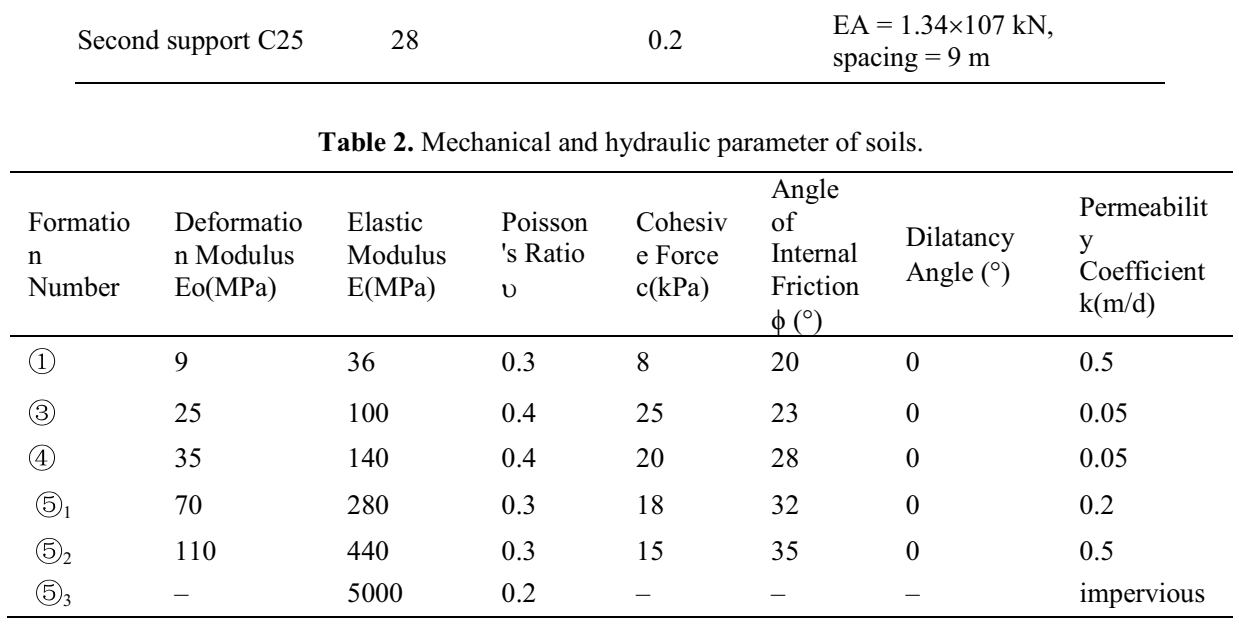

\subsection{Boundaries and Contact Conditions}

As for boundary conditions: The upper boundary is free. The $\mathrm{Y}$ displacement of the lower boundary as well as the $\mathrm{X}$ displacement of the left and right boundary is fixed as 0 .

Considering the deformation of the soil caused by the foundation pit excavation is tiny, the contacts are set as TIE contact between soil and the tunnel envelope structure as well as soil and the supporting structure of the foundation pit.

\subsection{Construction Conditions}

Combined with the practical construction process of a foundation pit and the needs of numerical analysis, the construction process is divided into working conditions below:

a) Working condition 1: The first layer of soil in the foundation pit is excavated and the first displacement field is obtained by balance calculation.

b) Working condition 2: Set up the first inner support and the first dewatering inside the foundation pit.

c) Working condition 3: The second layer of soil is excavated and the second displacement field is obtained by balance calculation.

d) Working condition 4: Set up the second inner support and the second dewatering inside the foundation pit.

e) Working condition 5: The third layer of soil is excavated and the last displacement field is obtained by balance calculation.

\section{Results of Analysis}

\subsection{Variation Law of Bending Moment in Tunnel}

Figure 2(a) and figure 2(b) show the bending moment diagram of the tunnel lining when the excavation got to the bottom of the foundation pit (working condition 5). The bending moment of the two tunnels is similar: The top and the bottom of the tunnel 
reach the minimum bending moment, towards the inside of the tunnel and the horizontal sides reach the maximum, towards the outside of the tunnel. This is mainly because the horizontal load of the surrounding soil is unloaded together with the excavation. The horizontal force of the tunnel decreases while the vertical direction remains unchanged, resulting in the bending moment of the tunnel presents a trend of compression up and down, and tension from left to right. Noting that the bending moment diagram of the tunnel is not completely horizontal, but rotates counterclockwise along the central symmetric position. This is mainly because the location of the tunnels is flush with the foundation pit bottom, and the maximum unloading amplitude of the foundation pit is generally close to the central position of the depth, which is above the buried depth of the tunnels. That is why the bending moment diagram of the tunnel tends to rotate counterclockwise.

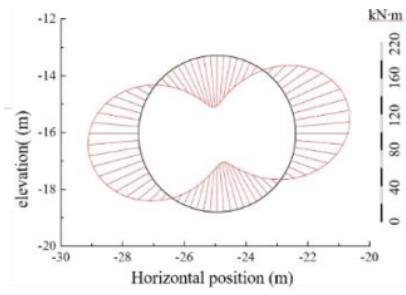

a) Vector diagrams of moment of left tunnel.

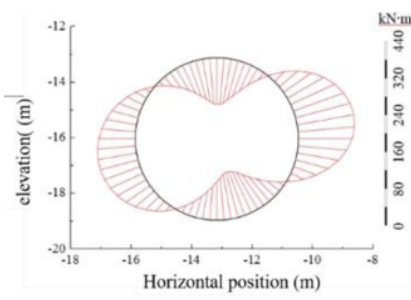

b) Vector diagrams of moment of right tunnel.

Figure 2. Vector diagrams of moment of each tunnel on the 5th working condition.

The overall bending moment value of the right tunnel is about twice that of the left one, which is mainly because compared with the left tunnel, the right one is closer to the foundation pit and the horizontal load decreases more. Noting that the bending moment the left side of the right tunnel and right side of the left tunnel is relatively smaller. For example, according to the bending moment change law mentioned above, the maximum bending moment on the left side of the right tunnel MR-L should be significantly larger than that of the left tunnel ML-L, but the value of MR-L obtained by numerical simulation is relatively similar to ML-L. Chances are that the soil between the two tunnels is restricted by the tunnel, which makes the stress change of this part of the soil less.

\subsection{Variation Law of Tunnel Shear Force}

Figure 3 shows the vector diagram of tunnel shear force under working condition5. Similar to the bending moment law, the shear force value of the right tunnel is also about twice that of the left tunnel, indicating the less secure of the right tunnel. For this twin-track tunnel, the maximum or minimum shear force appears at the position where the bending moment is 0 , and the maximum shear force appears at $45^{\circ}$ upper left and $45^{\circ}$ lower right. The minimum shear force occurs at $45^{\circ}$ lower left and $45^{\circ}$ upper right. Therefore, for the sake of avoiding the impact of shear stress on the tunnel as far as possible, it is suggested to avoid the design of lining joints in the four directions of the tunnel: $45^{\circ}$ upper left, $45^{\circ}$ lower left, $45^{\circ}$ upper right and $45^{\circ}$ lower right. 


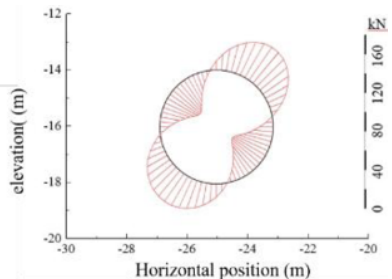

a) Vector diagrams of shear force of left tunnel.

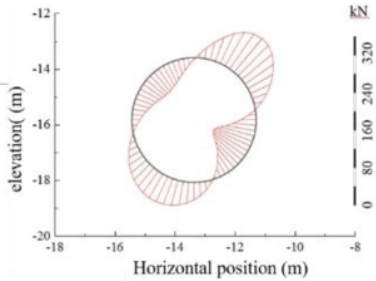

b) Vector diagrams of shear force of right tunnel.

Figure 3. Vector diagrams of shear force of each tunnel on 5th working condition.

\subsection{Tunnel Deformation Law}

Figure 4 and figure 5 respectively show the deformation diagram and aberration nephogram of the soil around the foundation pit under working condition 5. Consistent with the stress analysis, the soil shows a certain degree of deformation and the closer it is to the foundation pit, the greater the deformation. In the middle of the foundation pit, the soil shows the maximum deformation. As can be seen from the aberration nephogram, the deformation of the soil in the left tunnel is about $5 \mathrm{~mm}$, while that in the right tunnel is about $10 \mathrm{~mm}$. From the tunnel deformation diagram we can observe that the deformation of the right tunnel is larger. As in figure 2, the right tunnel appears as a flat ellipse with horizontal tension and vertical compression.

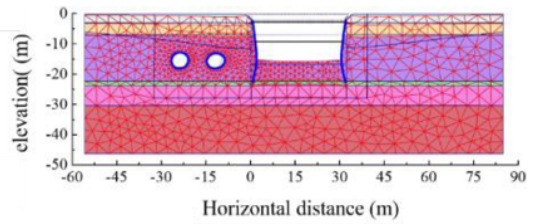

Figure 4. Sketch map of the deformation of soil (displacements scaled up 100 times).

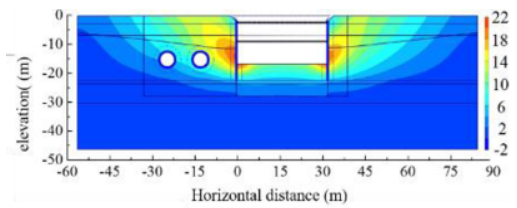

Figure 5. Nephogram of total displacements of soil.

Figure 6 shows the development law of the displacement of the tunnels under different working conditions. As we can see, the deformation of the tunnels keeps getting larger with the excavation of the foundation pit. When the excavation elevation is still at the upper part of the tunnel (working conditions 1 4), it affects the tunnels little, and the total displacement generated by the four working conditions accounts for about $50 \%$ of the total deformation. However, the tunnel settlement increases sharply from working condition 4 to 5 . This is mainly because the excavation elevation of the foundation pit has not arrived the buried depth of the tunnels yet in the working condition 4, which influences the tunnels little as it is said above. Once the excavation depth exceeds the buried depth of the tunnels, the unloading effect becomes obvious, and the deformation of the tunnel will sharply increase in this situation. Therefore, the buried depth of tunnel is an important factor of whether the tunnel will be influenced by the excavation of a foundation pit. Considering that the existing urban foundation pit is generally deep, usually ranging from 5 to $20 \mathrm{~m}$, it is recommended that the tunnel be buried at a depth of $20 \mathrm{~m}$ in order to minimize the possible impact of the tunnel during operation. 


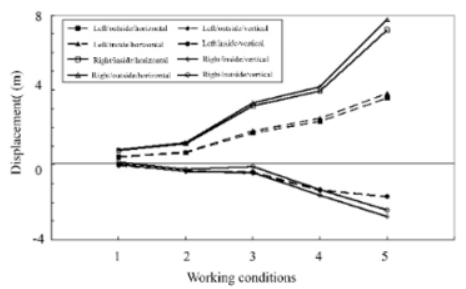

Figure 6. Deformation rule of twin-track tunnels.

\section{Conclusions}

In this paper, the numerical simulation method is applied to study the influence of foundation pit excavation on the deformation of adjacent twin-track tunnels, and the following conclusions are drawn:

(1) Under the influence of the excavation of a foundation pit nearby, the bending moment of the tunnels has the trend of compression at the upper and lower and tension at the left and right. On the whole, the bending moment value of the right tunnel is twice that of the left one. The bending moment of the sides facing the soil between tunnels is relatively smaller.

(2) Under the influence of the excavation of a foundation pit nearby, the maximum shear values of the tunnel appear at $45^{\circ}$ upper left and $45^{\circ}$ lower right. The minimum shear values appear at $45^{\circ}$ lower left and $45^{\circ}$ upper right. On the whole, the shear force of the right tunnel is twice that of the left one.

(3) Both the tunnels have a deformation trend of flat elliptical shape which is squeezed up and down and raised left and right due to the excavation of an adjacent foundation pit. The deformation of the right tunnel is obvious while that of the left one is smaller. That deformation is affected by the excavation depth of the foundation pit. Before the excavation depth reaches the buried depth of the tunnels, the deformation of is small. Once the buried depth is reached, the tunnel deformation will sharply increase.

\section{References}

[1] Ou CY, Hsieh PG and Chiou DC. Characteristics of ground surface settlement during excavation. Canadian Geotechnical Journal. 1993 Jun; 30(5): 758-767.

[2] Wu YD, Liu J, Ng CWW. Effects of pile extraction and refilling with cement slurry on ground settlements. Canadian Geotechnical Journal. 2013 Jul; 50(3): 343-349.

[3] Burford D. Heave of tunnels beneath the shell center London 1959-1986. Geotechnique. 1988 Mar; 38(1): 135-137

[4] Chang CT, Sun CW, Duann SW, et al. Response of a Taipei Rapid Transit System (TRTS) tunnel to adjacent excavation. Tunnelling and Underground Space Technology. 2001 Aug; 16(3): 151-158.

[5] Sharma JS, Hefny AM, Zhao J, et al. Effect of large excavation on deformation of adjacent MRT tunnels. Tunnelling and Underground Space Technology. 2001 May; 16(2): 93-98.

[6] Liu H, Li P and Liu J. Numerical investigation of underlying tunnel heave during a new tunnel construction. Tunnelling and Underground Space Technology. 2011 Jun; 26(2): 276-283. 